\title{
BMJ Open Patient perspectives on integrated healthcare for HIV, hypertension and type 2 diabetes: a scoping review
}

\author{
Sabine Singh, ${ }^{1,2}$ Ole Kirk, ${ }^{3}$ Shabbar Jaffar (D) , ${ }^{4}$ Catherine Karakezi, ${ }^{5}$ \\ Kaushik Ramaiya, ${ }^{6}$ P Kallestrup, ${ }^{2,7}$ Christian Kraef (i) ${ }^{2,3,8}$
}

To cite: Singh S, Kirk 0, Jaffar S, et al. Patient perspectives on integrated healthcare for HIV, hypertension and type 2 diabetes: a scoping review. BMJ Open 2021;11:e054629. doi:10.1136/ bmjopen-2021-054629

- Prepublication history and additional supplemental material for this paper are available online. To view these files, please visit the journal online (http://dx.doi.org/10.1136/ bmjopen-2021-054629)

Received 21 June 2021 Accepted 21 October 2021

Check for updates

(C) Author(s) (or their employer(s)) 2021. Re-use permitted under CC BY-NC. No commercial re-use. See rights and permissions. Published by BMJ.

For numbered affiliations see end of article.

Correspondence to

Dr Christian Kraef;

christiankraef@gmail.com

\section{ABSTRACT}

Introduction Antiretroviral therapy has reduced mortality and led to longer life expectancy in people living with HIV. These patients are now at an increased risk of noncommunicable diseases (NCDs). Integration of care for HIV and NCDs has become a focus of research and policy. In this article, we aim to review patient perspectives on integration of healthcare for HIV, type 2 diabetes and hypertension.

Methods The framework for scoping reviews developed by Arksey and O'Malley and updated by Peter et al was applied for this review. The databases PubMed, Web of Science and Cochrane library were searched. Broad search terms for HIV, NCDs (specifically type 2 diabetes and hypertension) and healthcare integration were used. As the review aimed to identify definitions of patient perspectives, they were not included as an independent term in the search strategy. References of included publications were searched for relevant articles. Titles and abstracts for these papers were screened by two independent reviewers. The full texts for all the publications appearing to meet the inclusion criteria were then read to make the final literature selection.

Results Of 5502 studies initially identified, 13 articles were included in this review, of which $11 \mathrm{had}$ a geographical origin in sub-Saharan Africa. Nine articles were primarily focused on HIV/diabetes healthcare integration while four articles were focused on HIV/ hypertension integration. Patient's experiences with integrated care were reduced HIV-related stigma, reduced travel and treatment costs and a more holistic personcentred care. Prominent concerns were long waiting times at clinics and a lack of continuity of care in some clinics due to a lack of healthcare workers. Non-integrated care was perceived as time-consuming and more expensive. Conclusion Patient perspectives and experiences on integrated care for HIV, diabetes and hypertension were mostly positive. Integrated services can save resources and allow for a more personalised approach to healthcare. There is a paucity of evidence and further longitudinal and interventional evidence from a more diverse range of healthcare systems are needed.

\section{INTRODUCTION}

Worldwide, 37.7 million people are living with HIV, of which 24.5 million are on treatment. There were 680000 AIDS-related deaths and

\section{Strengths and limitations of this study}

- We conducted a systematic review of patient perspectives on integrating healthcare for HIV and noncommunicable diseases using the framework for scoping reviews developed by Arksey and 0'Malley and updated by Peter et al.

- The scoping review methodology and broad search terms, reflected in more than 5500 initial records identified, ensure a high sensitivity of our search strategy covering all settings and levels of healthcare systems.

- As the review aimed to identify all relevant definitions of patient perspectives, they were not included as an independent term in the search strategy, allowing us to scope the variety of concepts and definitions used in the literature.

- A limitation of the current scoping review is the singular focus on type 2 diabetes and hypertension as indicator conditions, while other important diseases for integration not covered would be mental health, cardiovascular disease or chronic kidney disease.

1.7 million new infections in 2020. ${ }^{1}$ Global health programmes and related funding streams such as those supported by American President's Emergency Plan for AIDS Relief or the Global Fund have since 2003 facilitated the development of separate, vertical HIV-focused healthcare infrastructure across sub-Saharan Africa (SSA). ${ }^{2}$ This has led to an increased coverage with antiretroviral therapy (ART) and in consequence to longer life expectancy in people living with HIV (PLWH). However, at the same time, this has contributed to fragmentation in health systems in countries in Africa. ${ }^{3}$ Over the last decade, an increase in the burden of non-communicable diseases (NCDs) has been seen among PLWH, to a large degree due to better survival and general health status. ${ }^{45}$ In parallel, the prevalence of NCDs in the general population, in particular type 2 diabetes (T2D) and hypertension (HT) has increased significantly across SSA. ${ }^{6}$ It is 
estimated that 40.5 million $(71 \%)$ of the 56.9 million worldwide deaths were from NCDs in 2016 and the highest risks of dying from NCDs were observed in lowincome and middle-income countries, especially in SSA. ${ }^{7}$ Therefore, healthcare systems strengthening, increased investments and efficient use of resources are needed to counter the double burden of communicable and NCDs in SSA. ${ }^{8}$ The established vertical healthcare structures in many countries, in particular those for HIV-care, risk contributing to inefficient use of resources and increased HIV-related stigma. ${ }^{9} 10$

Thus, integration of the existing communicable and non-communicable healthcare infrastructure has become a recent policy and research focus to improve care for people living with NCDs (PLWNCDs) and PLWH alike. ${ }^{11}$ Integrated care can be defined as 'the coordination, colocation or simultaneous delivery of communicable and non-communicable services to patients who need it, when they need it. ${ }^{, 5}$ Integration of HIV and NCDs services can be categorised as (1) community-based integrated HIV/ NCDs screening in the general population, (2) screening for NCDs and their risk factors among PLWH, (3) integrated care of HIV/NCDs in healthcare facilities, (4) differentiated care for stable HIV/NCDs and (5) integrated population health for all patients with any need. ${ }^{12}$ Taking T2D and HT as an example, potential benefits could be better control of HT and T2D, earlier diagnosis, better management and disease control, and cost saving for patients through inclusion in routine HIV control. Accordingly, benefits for HIV-control could be easier access to HIV services and the reduction of stigma. ${ }^{13} \mathrm{~A}$ potential downside to integration can be longer waiting times for patients if integration is done with reduced resources compared with the current standard care. ${ }^{14}$

Patients' knowledge, attitudes, beliefs, desires and practices have a large influence on the successful delivery of healthcare. ${ }^{15}$ Recently, quality of life has been proposed as the fourth 90 to complement the Joint United Nations Programme on HIV/AIDS (UNAIDS) 90-90-90 targets to monitor the global HIV response, which requires a better understanding of patient reported outcomes. ${ }^{16}$ However, little is known about patient perspectives on integration of healthcare for HIV and NCDs. ${ }^{13}$

\section{Objective and aims}

The objective of this scoping review was to identify, describe and analyse the peer-reviewed literature on patient perspectives on healthcare integration for HIV and NCDs. T2D and HT were used as indicator conditions for NCDs as they represent a large proportion of the NCD burden, in particular in PLWH, are well-defined and most commonly used as indicator conditions in published research on $\mathrm{HIV} / \mathrm{NCD}$ integration.

Specifically, we aimed to identify the scope and describe the peer-reviewed literature on patient perspectives. Furthermore, we reviewed frameworks and methodologies used to assess patient perspectives on HIV/ NCD healthcare integration as well as the findings and potential recommendations of the available literature on integration of HIV and NCD services.

\section{Research questions}

1. Which kind of research (quantitative, qualitative) exists and what methodologies were used?

Rationale: To date, no systematic review of patient perspectives on integrated healthcare exists. Describing the evidence, kind of research and methodologies in a systematic way helps identifying research gaps and plan for future research.

2. In what settings (geographical, healthcare system, socioeconomic context) has research been conducted?

Rationale: We report findings by geographical setting, healthcare system context and socioeconomic group, as approaches to healthcare integration can differ widely depending on the situation.

3. How are patient perspectives conceptualised?

Rationale: To the best of our knowledge, no standard or best-practice conceptualisation for assessing patient perspectives on healthcare provision exists. Identifying the concepts used can help standardise and compare patient perspectives across studies and settings.

4. What are patient perspectives on integration of HIV/

NCD services?

- What are the perspectives of PLWNCDs on integration of T2D and/or HT care with HIV care?

- What are the perspectives of PLWH on integration of HIV care with T2D and/or HT care?

Rationale: Describing patient perspectives on integration of HIV/NCD services can inform policy-makers, researchers and healthcare providers to design effective, patient-centred, healthcare interventions.

\section{METHODS}

A scoping review is a method of reviewing evidence-based research to, scope a body of literature, clarify concepts, identify knowledge gaps or to investigate research conduct. ${ }^{17}$ The framework for scoping reviews developed by Arksey and O'Malley and updated by Peters $e t$ al was applied for this study. ${ }^{18} 19$ This method of a scoping review was chosen over a more focused systematic review to apply a broader approach to the vaguely defined theme in order to map the available literature on this topic, and to identify research gaps. ${ }^{18}$ In the preparation of this review a research protocol was created according to the Preferred Reporting Items for Systematic Reviews and Meta-Analyses extension for Scoping Reviews checklist to ensure quality, transparency and complete reporting. ${ }^{20}$

\section{Patients and public involvement}

Patients and the public were indirectly represented in the design, conduct and reporting of this review as several of the authors are representatives of patient associations (Danish NCD Alliance, East Africa NCD Alliance). The development of the research question(s) and outcome measures was driven by the experience of the authors 


\begin{tabular}{|c|c|}
\hline Category & Definitions \\
\hline PLWH/PLWA & $\begin{array}{l}\text { PLWH/PLWA are defined according to the definition by the UNAIDS Terminology Guidelines from } 2015 \\
\text { as persons, who are seropositive for HIV. }{ }^{36}\end{array}$ \\
\hline NCDs & $\begin{array}{l}\text { NCDs are characterised by WHO as being non-transmissible and often known as chronic diseases. } \\
\text { They are a result of combinations of genetic, physiological, environmental and behavioural factors. They } \\
\text { are largely preventable and are linked to common risk factors and underlying determinants. }{ }^{37} \text { In this } \\
\text { review, we chose to focus on type } 2 \text { diabetes mellitus and hypertension as indicator conditions, which } \\
\text { have seen a rapid increase in prevalence, especially in SSA. }\end{array}$ \\
\hline Integrated healthcare & $\begin{array}{l}\text { For integrated healthcare we used the definition of the WHO Europe Regional Office: 'an approach } \\
\text { to strengthen people-centred health systems(...)delivered by a coordinated multidisciplinary team of } \\
\text { providers working across settings and levels of care(...).'34 }\end{array}$ \\
\hline $\begin{array}{l}\text { Patient perspectives } \\
\text { (PP) }\end{array}$ & $\begin{array}{l}\text { There is no unique consensus or definition for PP. }{ }^{15} \text { For the purpose of this review we defined PP as } \\
\text { the experiences, values, preferences, expectations, concerns and opinions expressed by patients (in } \\
\text { our case PLWNCDs or PLWH). They can broadly be categorised as those perspectives expressed } \\
\text { by individually concerned patients and those expressed by informally or formally selected patient } \\
\text { representatives (eg, civil society organisations). They can be reported directly by patients or indirectly } \\
\text { through healthcare providers or other secondary sources. }\end{array}$ \\
\hline
\end{tabular}

NCDs, non-communicable diseases; PLWA, people living with AIDS; PLWH, people living with HIV; PLWNCDs, people living with NCDs; SSA, sub-Saharan Africa.

as representatives of patient associations. However, no patients were involved directly in the planning and conduct of this study. The results will be disseminated to patient representatives and associations (eg, the Global NCD Alliance and East Africa NCD Alliance).

\section{Definitions}

The definitions of PLWH/PLWA (people living with AIDS), NCDs, integrated healthcare and patient perspectives are provided in table 1 . As the review aimed to identify definitions of patient perspectives, they were not included as an independent term in the search strategy.

\section{Databases and search strategy}

The databases PubMed, Web of Science and Cochrane library were searched. Broad terms were included in the search strategy (table 1). HIV, NCDs (specifically T2D and $\mathrm{HT}$ ) and healthcare integration were the three main categories the search strategy was based on. The search strategy for PubMed and Cochrane library consisted of free text and Medical Subject Headings terms. The search strategy used in PubMed is presented in table 2, and the search terms used in the other databases are presented in online supplemental tables 1 and 2. A librarian at the University of Aarhus was consulted to support the development of the search terms. Reference lists of included publications were searched for relevant articles.

\section{Criteria for inclusion and exclusion}

Inclusion criteria

- Peer-reviewed articles (including original quantitative and qualitative studies, systematic reviews, editorials, commentaries, viewpoints) on integration of healthcare for HIV and T2D and/or HT which provide information on patient perspectives (according to definitions in table 1).
- Published between 1 January 1990 and 1 March 2021.

- Publications in English, German, French and Danish.

\section{Exclusion criteria}

- Book chapters and grey literature (dissertations, conference proceedings, reports, etc).

\section{Literature selection}

The citation software Zotero was used to merge and remove the duplicates among the results. Titles and abstracts for these papers were thoroughly screened using Rayyan (a web and mobile app for systematic reviews) by two independent reviewers (SS and CK). The full texts for all the publications appearing to meet the inclusion criteria were read to make the final literature selection. Any disagreements between the two reviewers at any stage of the study selection were resolved by a third reviewer (PK).

\section{Data collection and extraction}

Data on origin of author, year of publication, geographical focus of the publication, publication type, type of NCD, definition of healthcare integration, definition of patient perspectives, assessment method for patient perspectives and the content of the patient perspectives were extracted and transferred into a prespecified extraction sheet (SS). These data were used to facilitate analysis and development of figures and summarising tables. A second researcher independently checked the data for accuracy and detail (CK). Disagreements were resolved by consensus.

\section{Data analysis}

The extracted information were analysed according to the research questions stated above and summarised systematically. Additional important themes reported 
Table 2 Search terms used in PubMed

\begin{tabular}{|c|c|}
\hline Category & PubMed search strategy \\
\hline HIV & $\begin{array}{l}\text { 1. HIV infections } \\
\text { 2. Human immunodeficiency virus } \\
\text { 3. AIDS } \\
\text { 4. } 1 \text { OR } 2 \text { OR } 3\end{array}$ \\
\hline $\begin{array}{l}\text { NCDs, } \\
\text { diabetes mellitus } \\
\text { type } 2 \text { and } \\
\text { hypertension }\end{array}$ & $\begin{array}{l}\text { 5. Noncommunicable diseases } \\
\text { 6. NCDs } \\
\text { 7. NCD } \\
\text { 8. Diabetes Mellitus Type } 2 \\
\text { 9. ((type } 2 \text { OR type ii OR "noninsulin } \\
\text { dependent" OR "non insulin } \\
\text { dependent" OR "adult onset" OR } \\
\text { "maturity onset" OR obes*) AND } \\
\text { diabet*) } \\
\text { 10. T2dm } \\
\text { 11. Tiidm } \\
\text { 12. Hypertension } \\
\text { 13. Hypertensi* } \\
\text { 14. Prehypertension } \\
\text { 15. Pre hypertension } \\
\text { 16. prehypertensi* } \\
\text { 17. Blood pressure } \\
\text { 18. bp } \\
\text { 19. } 5 \text { OR } 6 \text { OR } 7 \text { OR } 8 \text { OR } 9 \text { OR } 10 \text { OR } 11 \\
\text { OR } 12 \text { OR } 13 \text { OR } 14 \text { OR } 15 \text { OR } 16 \text { OR } \\
\text { 17 OR } 18\end{array}$ \\
\hline
\end{tabular}

$\begin{array}{ll}\text { Healthcare } & \text { 20. } \begin{array}{l}\text { Integrated delivery systems } \\ \text { integration }\end{array} \\ 21 . & \text { (vertical OR horizontal OR integrat* } \\ & \text { OR integrated OR coordinat* OR } \\ & \text { coordinated OR co-ordinat* OR co- } \\ & \text { ordinated OR link }{ }^{*} \text { OR linked) AND } \\ & \text { (program* OR care OR service*) OR } \\ & \text { delivery of health care OR primary } \\ & \text { health care OR integrat* OR health } \\ & \text { care OR health-care OR healthcare OR } \\ & \text { health service } \\ \text { 22. } & 20 \text { OR } 21\end{array}$

4 AND 19 AND 22

NCDs, non-communicable diseases.

by the included studies not covered by the predefined research questions were described in a narrative way.

\section{RESULTS}

\section{Search results}

After removal of duplicates, 5502 articles were identified. 5486 publications did not match the inclusion criteria and were excluded after review of titles and abstracts by two independent reviewers. Full texts were retrieved for 20 articles. Of these, 13 were eligible ${ }^{10121-31}$ for inclusion, 7 were excluded during the assessment of full texts (figure 1).

\section{Characteristics of included studies}

All included publications were original research articles, used cross-sectional study designs, and were published between 2016 and 2021. All were qualitative studies, and all except two ${ }^{14}{ }^{29}$ used semistructured interviews, ${ }^{27}$ in-depth interviews ${ }^{1022} 243031$ or a combination of

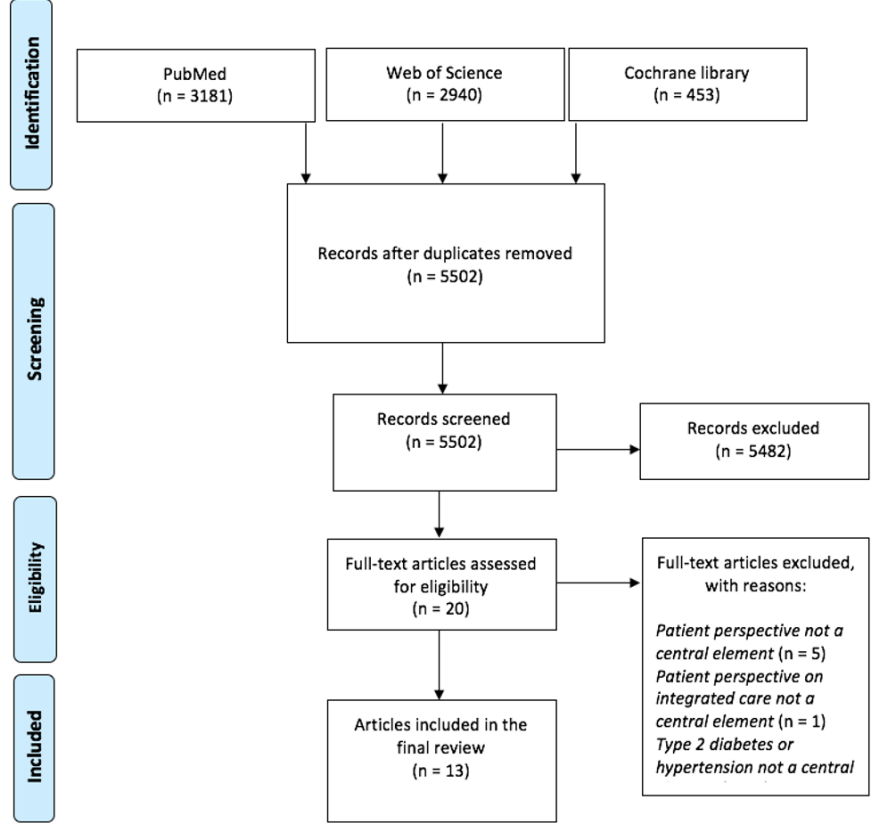

Figure 1 PRISMA flow chart of the flow of studies through each phase of the review process. PRISMA, Preferred Reporting Items for Systematic Reviews and Meta-Analyses.

these e1 $2628^{2}$ (table 3). Some studies combined the interviews with instruments such as focus group discussions and patient observations. A majority of the studies $(n=7)$ had their origin/geographical focus in South Africa (SA). One study was conducted in Kenya, ${ }^{22}$ Tanzania, ${ }^{31}$ Uganda, ${ }^{30}$ Malawi, ${ }^{29}$ Northern Thailand ${ }^{27}$ and North Carolina (USA), respectively ${ }^{28}$ (table 3).

\section{Study settings, healthcare systems and socioeconomic contexts}

An overview of the study settings, healthcare systems and socioeconomic contexts is provided in table 4 . The articles described diverse healthcare systems regarding the integration of HIV, HT and T2D healthcare services ranging from no integration to the integration of some elements, such as integrated medication refill systems for HIV, diabetes mellitus (DM) and HT patients. ${ }^{22}{ }^{26}$ The presented concepts of healthcare integration were likewise diverse. Many studies from $\mathrm{SA}^{2123-26}$ used the Integrated Chronic Disease Management (ICDM) ${ }^{32}$ framework, which was introduced in SA between 2011 and 2013. The ICDM model was introduced as a response to the double burden of HIV and NCDs with a vision of providing integrated prevention, treatment and care of chronic patients at Primary Health Care (PHC) level to ensure a seamless transition to assisted self-management within the community by leveraging HIV programmes. ${ }^{25} 32$ The model consists of four interrelated components; facility reorganisation (administrative and patient flow), clinical supportive management (clinical mentorship), assisted self-support (adherence support) and strengthening of support systems outside the facility. ${ }^{23} 32$

Some places in $\mathrm{SA}^{2124}$ and Thailand ${ }^{27}$ reported separate healthcare clinics for HIV and T2D. In Free State 
Table 3 Overview of geographical origin, research type and methodology of included studies

\begin{tabular}{|c|c|c|c|c|}
\hline & Patient population & Geographical focus & Research type & $\begin{array}{l}\text { Assessment method for patient } \\
\text { perspectives }\end{array}$ \\
\hline Matima et $a l^{21}$ & PLWH & $\begin{array}{l}\text { Khayelitsha, Cape } \\
\text { Town, SA }\end{array}$ & Qualitative & $\begin{array}{l}\text { Individually face-to-face } \\
\text { semistructured, in-depth interviews } \\
\text { (IDIs) in English. The IDIs were } \\
\text { conducted in a private room in } \\
\text { the clinic with the presence of a } \\
\text { translator. }\end{array}$ \\
\hline Lebina et $a l^{23}$ & $\begin{array}{l}\text { PLWH and } \\
\text { PLWNCDs }\end{array}$ & $\begin{array}{l}\text { Dr. Kenneth Kaunda } \\
\text { district and West Rand } \\
\text { district, SA }\end{array}$ & Qualitative & $\begin{array}{l}\text { Structured interviews (including } \\
\text { standardised open-ended and } \\
\text { closed fixed-response questions) } \\
\text { of healthcare workers' (nurses, } \\
\text { administrators and ancillary } \\
\text { staff) perceptions of patient } \\
\text { responsiveness. Participants were } \\
\text { asked to identify facility specific } \\
\text { issues (context) that might hinder } \\
\text { or support implementation fidelity } \\
\text { of the ICDM model. }\end{array}$ \\
\hline Ameh et $a l^{25}$ & $\begin{array}{l}\text { PLWH and } \\
\text { PLWNCDs }\end{array}$ & Agincourt, SA & Qualitative & $\begin{array}{l}\text { Exit interviews followed by FGDs } \\
\text { of } 5-9 \text { patients of similar age (to } \\
\text { provide a conducive environment } \\
\text { to freely discuss) (each session } \\
1-1.5 \text { hours) and one separate } \\
\text { FGD for five clinical defaulters. } \\
\text { The FGDs were held in a neutral } \\
\text { venue within the catchment area } \\
\text { of the health facility to enable the } \\
\text { patients to freely express their } \\
\text { experiences. }\end{array}$ \\
\hline
\end{tabular}

Continued 
Table 3 Continued

\begin{tabular}{|c|c|c|c|c|}
\hline & Patient population & Geographical focus & Research type & $\begin{array}{l}\text { Assessment method for patient } \\
\text { perspectives }\end{array}$ \\
\hline Knight et $a^{26}$ & PLWH & $\begin{array}{l}\text { Langa and Khayelitsha, } \\
\text { Cape Town, SA }\end{array}$ & Qualitative & $\begin{array}{l}\text { Semistructured, IDIs with patients } \\
\text { and key informant interviews } \\
\text { (KII) with service providers to } \\
\text { triangulate data from patients. } \\
\text { The interviews of the patients } \\
\text { mostly took place in their homes. } \\
\text { The KII and few of the patient } \\
\text { interviews took place in a quiet } \\
\text { space within the facility or relevant } \\
\text { place of work where people felt } \\
\text { comfortable and privacy could be } \\
\text { ensured. }\end{array}$ \\
\hline Moise et $\mathrm{al}^{27}$ & PLWH & $\begin{array}{l}\text { Chiang Mai, Northern } \\
\text { Thailand }\end{array}$ & Qualitative & Semistructured interviews in Thai \\
\hline Mkumba et al ${ }^{28}$ & PLWH & $\begin{array}{l}\text { Durham, North } \\
\text { Carolina, US }\end{array}$ & Qualitative & $\begin{array}{l}\text { Semistructured IDIs in private } \\
\text { rooms in the clinic }\end{array}$ \\
\hline Moucheraud et al ${ }^{29}$ & PLWH & Lilongwe, Malawi & Quantitative & $\begin{array}{l}\text { Cross-sectional survey (were } \\
\text { multiple-choice or short-response) } \\
\text { and data from clinical records }\end{array}$ \\
\hline Peer et $a 1^{10}$ & PLWH & $\begin{array}{l}\text { Cape Town and } \\
\text { surrounding } \\
\text { municipalities, SA }\end{array}$ & $\begin{array}{l}\text { Quantitative and } \\
\text { qualitative }\end{array}$ & $\begin{array}{l}\text { Quantitative surveys (Likert-scale), } \\
\text { FGDs and IDIs }\end{array}$ \\
\hline Muddu et $a /^{30}$ & PLWH & $\begin{array}{l}\text { Tororo, Nagongera } \\
\text { Health } \\
\text { Centre IV, Mulanda } \\
\text { Health Centre IV) and } \\
\text { the Dis- trict Health } \\
\text { Office of Tororo } \\
\text { District, Eastern } \\
\text { Uganda }\end{array}$ & Qualitative & KIls, IDIs and FGDs \\
\hline Manavalan et a $\left.\right|^{31}$ & PLWH & $\begin{array}{l}\text { Moshi urban district, } \\
\text { Northern Tanzania }\end{array}$ & Qualitative & $\begin{array}{l}\text { IDI. The interview guide included } \\
\text { open ended questions on key } \\
\text { domains of interest, with each } \\
\text { question followed by a list of } \\
\text { possible probes to guide the } \\
\text { conversation }\end{array}$ \\
\hline
\end{tabular}

FGDs, focus group discussions; ICDM, Integrated Chronic Disease Management; IDI, In-depth Interview

; MAC, Medication Adherence Clubs; PLWH, people living with HIV; PLWNCDs, people living with NCDs; SA, South Africa

and Agincourt (SA) some of the PHC clinics provided integrated care for T2D and HIV, while other PHC clinics did not have integrated care yet, though both studies only included the PHC clinics with integrated care. ${ }^{1425}$ In a clinic in Khayelitsha, ART and chronic care services were located at the same clinic but in different sections ${ }^{26}$ (table 4). A study from the Duke Adult Infectious Diseases Clinic in the USA reported that NCD-related healthcare could be provided at the HIV-clinic but almost half of the HIV clinic patients received chronic NCD care outside of the clinic. ${ }^{28}$ Finally, two studies described infrastructures of more complete integration in the form of Medication Adherence Clubs (MACs) ${ }^{22}$ and implementation of the
ICDM model into PHCs. ${ }^{23}$ The integrated MACs were established in 2013 in Kibera as a medication refill system for those with HIV, DM and HT. ${ }^{22}$

\section{Sociodemographic characteristics of the patients}

The number of included participants ranged from $10^{24}$ to more than $800 .{ }^{14}$ In all except one study, more female patients were included (table 4). ${ }^{26}$ Participant's age ranged from 18 to 70 years, but none included children $<18$ years. All studies, except one from the USA, were conducted in low-income or middle-income countries in SSA and Thailand. The participants were characterised by a low educational level, ${ }^{21}$ unemployment ${ }^{21}{ }^{24}$ and/ 


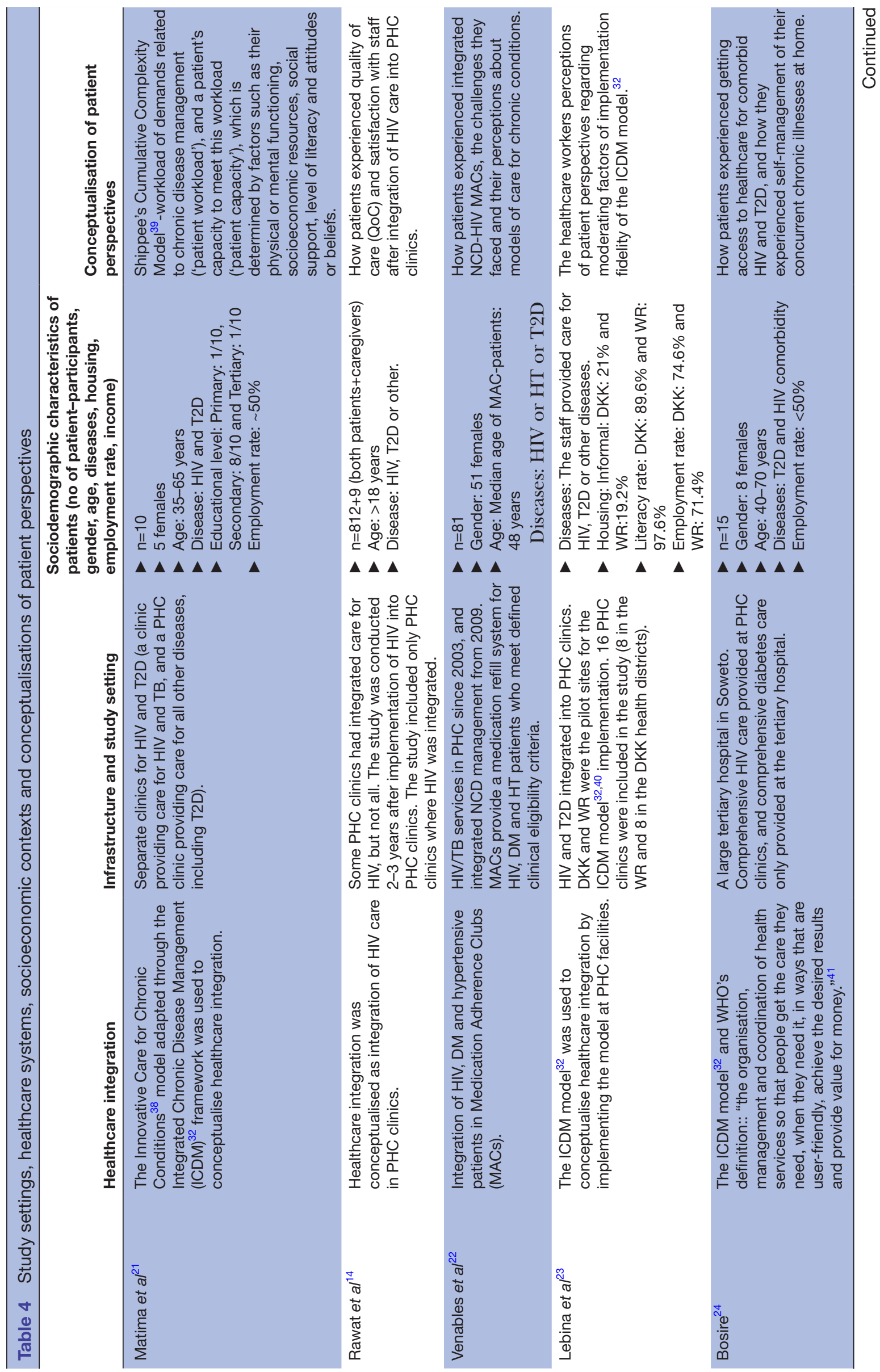




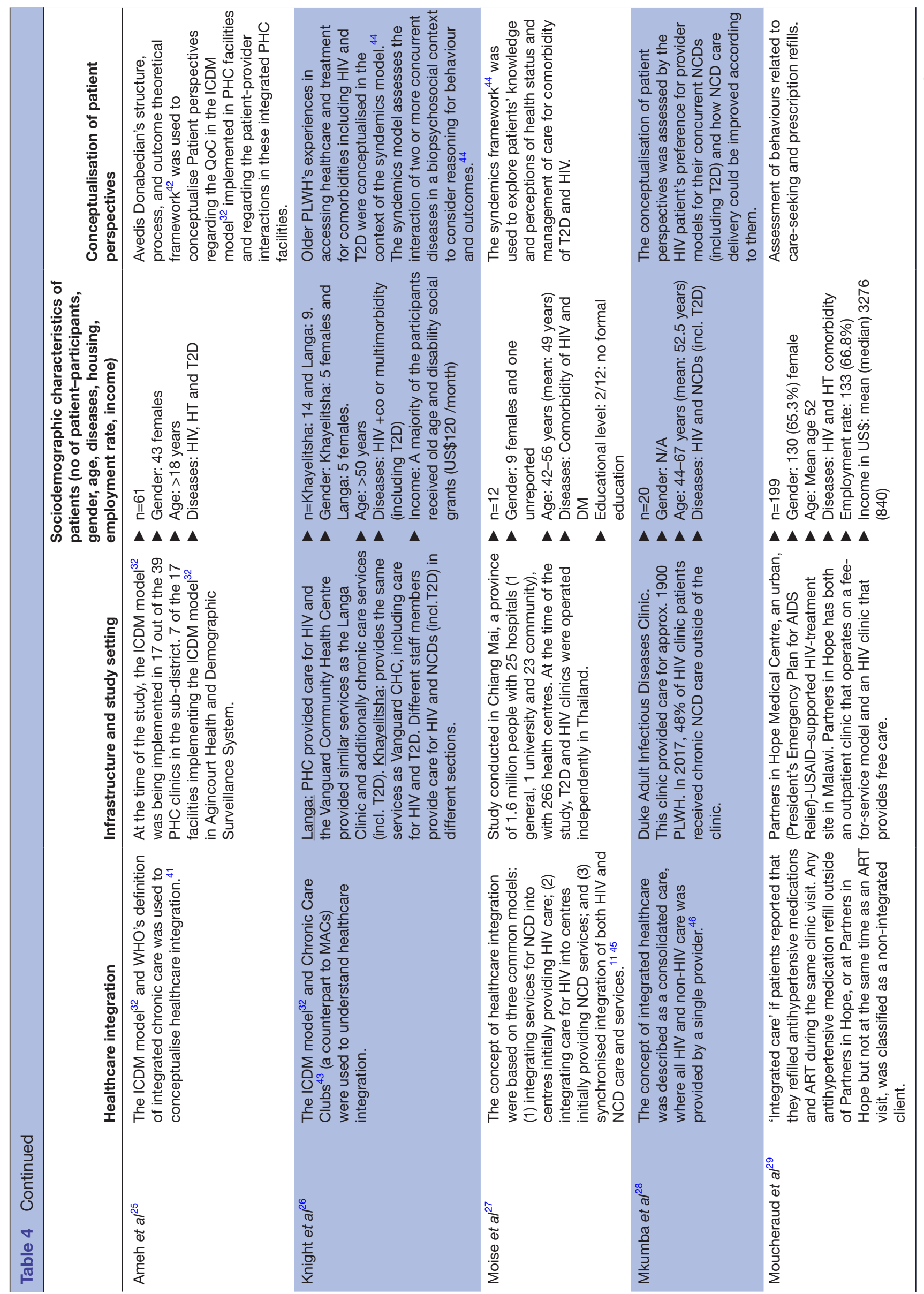




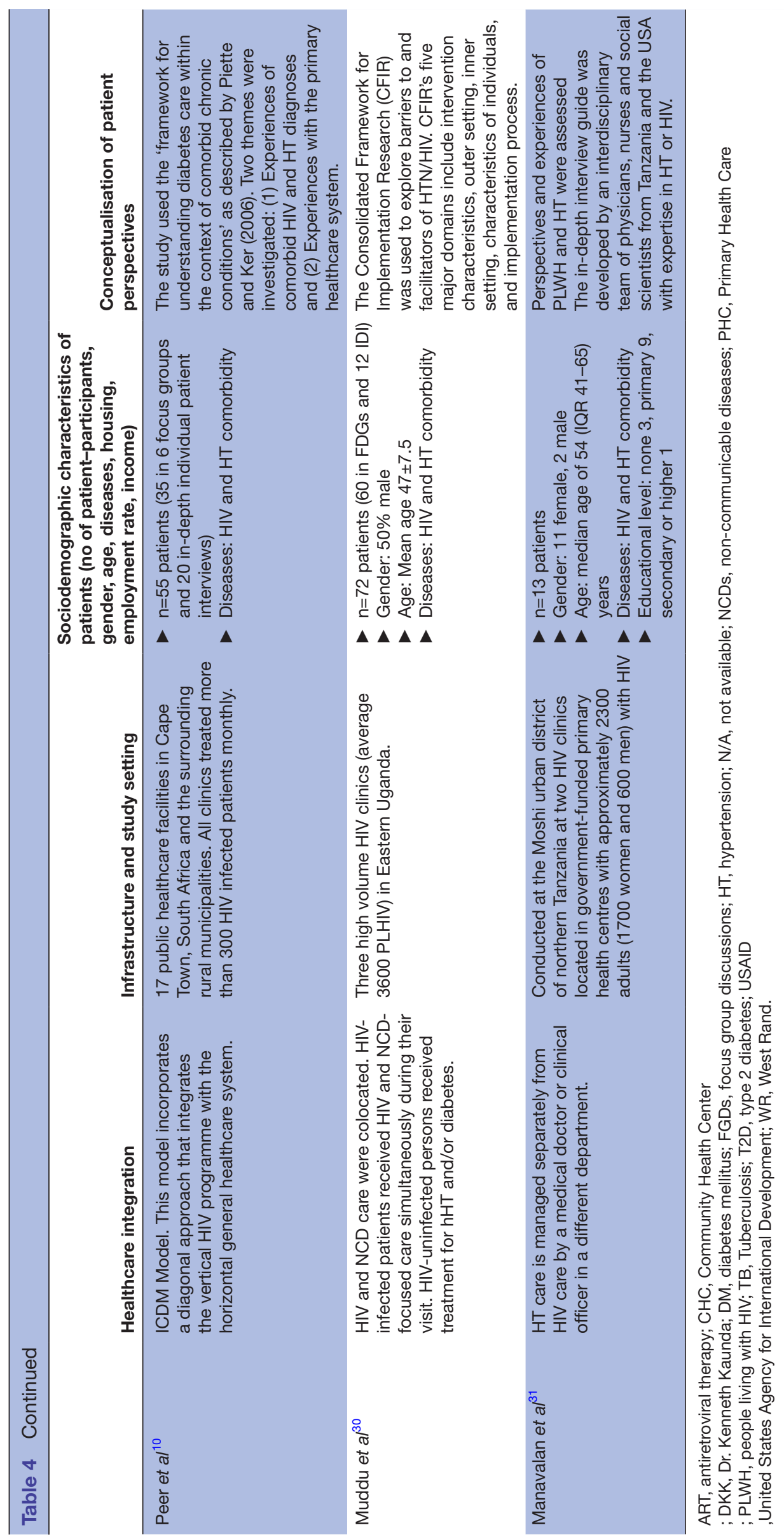


or living in informal settlements ${ }^{21}$ with limited financial resources. ${ }^{24}$

In the study by Lebina $e t a l,{ }^{23}$ the patient characteristics were not available and therefore not included, because the measure of the participants' responsiveness with regard to patients/users was assessed by measuring staff's perceptions of patient responsiveness.

\section{How were patient perspectives conceptualised?}

A diversity of models and approaches were used to conceptualise patient perspectives and are presented in table 4 .

\section{Emerging themes (patient perspectives)}

The most prominent themes among patient perspectives and experiences on healthcare integration were travel and treatment costs, appointment systems, waiting times at the facilities and HIV-related stigma(table 5).

\section{Travel and treatment costs}

Patients in Khayelitsha, Langa and Soweto (SA) experienced excessive travel costs due to multiple appointments at separate clinics for HIV and T2D. ${ }^{21}{ }^{24}{ }^{26}$ Some patients defaulted their appointments due to travel costs, which led to poor patient-provider relationships: 'If you come late or fail to come, the nurses will be shouting at you. But nobody really cares to know why I did not come. That's why I choose to stay at home some clinic days.' (patient).$^{24}$ In one of the facilities in Khayelitsha the services for NCDs (including T2D) and HIV were physically located in the same complex, but because the services were provided separately, the patients did not experience having coinciding appointments, and did therefore not save the travel expenses: '[...] No, it doesn't happen, I haven't had it yet [that the dates for the appointments coincide]. My appointments are separate.' (patient). ${ }^{26}$ PLWH with comorbid HT reported concerns for additional costs of transportation and lost wages when attending integrated medicine refill locations and therefore often preferred to choose location closer to home or with perceived lower costs. However, when assessing actual incurred cost those in the integrated care group reported lower annual cost (US\$21 on average) than those in the non-integrated group (US\$91 on average). Non-integrated care for HT and HIV in Northern Tanzania was also associated with higher cost for antihypertensive medication, provider visits, transport to the clinic and the expense of a healthy lifestyle. ${ }^{31}$ Participants attending integrated care for HIV and HT in Cape Town, South Africa reported that lower travel costs and time spent accessing different clinics increased the likelihood of treatment seeking behaviour and less defaulting. ${ }^{10}$

\section{Continuity of care and appointment systems}

As illustrated by the quote in the previous section, the facility in Khayelitsha (SA) did not provide coherent treatment for HIV and T2D even when the services were located in the same complex. ${ }^{26}$ In Langa (SA) on the other hand patients could experience having clashing appointments at two different clinics. ${ }^{26}$ Visiting numerous separate clinics led to patients in Soweto (SA) receiving conflicting information from clinicians, because of poor interprovider communication: 'Last week the rheumatologist told me that my bones are getting closer to each other, they have inserted metals in my right foot. When I attended the diabetes clinic, the doctor asked me to exercise because I was adding more weight, but I can't exercise because of the surgery they did on my leg. My ARVs have amplified my appetite' (patient). ${ }^{24}$

In Durham patients were satisfied with NCD care received from their HIV providers, and generally less satisfied receiving NCD care from their primary care provider (PCP). They experienced a stronger patientprovider relationship with their HIV providers compared with their PCP. Patients valued interprovider communication, which some found was great, while others perceived inadequacies in communication between their providers. Overall, the patients preferred an integrated care model where all their care was consolidated in one place, with one provider: 'I wish my HIV doctor could provide everything...If I could get all my care in one place that would be wonderful rather than travelling to different places' (patient) ${ }^{28}$

Patients in Free State were glad to receive more comprehensive services after the integration of HIV care in PHC clinics: 'I feel the treatment they give us is better than before. We are seen quicker and everything is checked. I'm tested every 3 months for HIV and my glucose and blood pressure is checked every visit.' (patient). ${ }^{14}$ While patients in Agincourt experienced rigid appointment systems after the implementation of the ICDM model into PHC facilities in which they were unable to access services for sudden-onset illnesses. ${ }^{25}$

In Cape Town, South Africa, PLWH and comorbid HT experienced a lack of continuity of care (different healthcare workers) but were generally glad for the more holistic treatment approach in the integrated healthcare clinics. $^{10}$

\section{Waiting times at the facilities}

Long queues and waiting times prior to appointments at the facilities were experienced by patients in Langa and Khayelitsha, especially pronounced prior to clinical appointments for T2D. In the context of HIV services this was not a problem, where advancements have been made through MACs, which avoided overcrowding and reduced waiting times at the health facilities. ${ }^{21}{ }^{26}$ The integrated MACs for HIV, T2D and HT were likewise experienced to be time saving and preventing long queues in Kibera (Kenya). ${ }^{22}$

In Free SA, where the PHC clinics had integrated care for HIV and NCDs, the patients experienced staff shortage leading to negative provision of quality services and long waiting times in queuing prior to consultations. ${ }^{14}{ }^{25}$ PLWH with comorbid HT in Cape Town also had concerns related to longer waiting times in integrated healthcare facilities. ${ }^{10}$ 
Table 5 Overview of key themes among patient perspectives for included studies (fragmented versus integrated care)

Fragmented versus integrated

Article care

Key themes among patient perspectives

\begin{tabular}{|c|c|c|}
\hline Matima et $\mathrm{al}^{21}$ & Fragmented care & $\begin{array}{l}\text { Travel costs. } \\
\text { Long waiting times outside the clinics prior to appointments. } \\
\text { Incoherent treatment. }\end{array}$ \\
\hline Rawat et al ${ }^{14}$ & Integrated care & $\begin{array}{l}\text { Larger no of patients attending the clinic leading to staff shortage. } \\
\text { Long waiting times outside the clinics prior to appointments. } \\
\text {.Poor confidentiality of medical records leading to increased HIV stigma } \\
\text { - Health education +more awareness of HIV leading to reduced HIV stigma. } \\
\text { Coherent services. }\end{array}$ \\
\hline
\end{tabular}

\begin{tabular}{|c|c|c|}
\hline Venables et $a l^{22}$ & Integrated care & $\begin{array}{l}\text { Integrated MACs considered acceptable: } \\
\text { Time saving. } \\
\text { Preventing long queues. } \\
\text { Provided people with health education and peer-support. } \\
\text { Reduced HIV-related stigma. } \\
\text { Non-MAC members: Not knowing the existence of the clubs and confusing eligibility } \\
\text { criteria }\end{array}$ \\
\hline Lebina et $a^{23}$ & Integrated care & $\begin{array}{l}\text { Separate medical records, waiting areas and queues leading to increased HIV } \\
\text { stigma. } \\
\text { - Poor compliance by patients: poor adherence to appointments and medications. }\end{array}$ \\
\hline Bosire $^{24}$ & Fragmented care & $\begin{array}{l}\text { Travel costs leading to patients' defaulted appointments leading to poor patient- } \\
\text { provider relationship. } \\
\text { Poor interprovider communication leading to incoherent treatment. }\end{array}$ \\
\hline Ameh et $\left.a\right|^{25}$ & Integrated care & $\begin{array}{l}\text { Rigid appointment systems. } \\
\text { Long waiting times because of long breaks and late arrival of staff. } \\
\text { Staff shortage leading to negative behaviour of staff members. }\end{array}$ \\
\hline Knight et $a^{26}$ & Fragmented care & $\begin{array}{l}\text { Travel costs. } \\
\text { Long waiting times prior to consultation } \\
\text { Incoherent treatment. } \\
\text { - Clashing appointments in Langa. }\end{array}$ \\
\hline Moise et $a l^{27}$ & Fragmented care & $\begin{array}{l}\text { Some people living with comorbid diabetes and HIV were satisfied with their current } \\
\text { separate treatments for HIV and T2D, while others uttered a desire for specialised } \\
\text { care for comorbid patients. } \\
\text { Some people living with comorbid diabetes and HIV would like even more privacy } \\
\text { for their HIV treatment. }\end{array}$ \\
\hline Mkumba et $a l^{28}$ & Fragmented care & $\begin{array}{l}\text { Satisfaction with NCD care received from HIV provider, and less satisfied receiving } \\
\text { NCD care from PCP. } \\
\text { Stronger patient-provider relationship with HIV provider than PCP. } \\
\text { Would value a stronger interprovider communication. } \\
\text { A desire for an integrated care model where all their care was consolidated in one } \\
\text { place, with one provider. } \\
\text { - Positive towards increased participation from HIV clinic support staff }\end{array}$ \\
\hline $\begin{array}{l}\text { Moucheraud et } \\
\left.a\right|^{29}\end{array}$ & $\begin{array}{l}\text { Fragmented and } \\
\text { integrated care }\end{array}$ & $\begin{array}{l}\text { Fragmented (non-integrated care) } \\
\text { Additional costs (ie, beyond costs already incurred for ART visits), costs of } \\
\text { transportation to refill visits and lost wages during refill visits. } \\
\text { Refill location for medicines chosen primarily due to perceived lower medication } \\
\text { costs and proximity/convenience (eg, distance to home). } \\
\text { Integrated care } \\
\text { Lower annual care-seeking costs (US } \$ 21 \text { on average) than those in the non- } \\
\text { integrated care group (US } \$ 91 \text { on average). }\end{array}$ \\
\hline
\end{tabular}


Table 5 Continued

\begin{tabular}{|c|c|c|}
\hline Article & $\begin{array}{l}\text { Fragmented } \\
\text { versus integrated } \\
\text { care }\end{array}$ & Key themes among patient perspectives \\
\hline Peer et $a l^{10}$ & Integrated care & $\begin{array}{l}\text { Removal of stigma attached to attending ART-clinic. } \\
\text { Long waiting times at clinics, being attend to later than other (non-HIV) patients. } \\
\text { Lack of continuity of care (different healthcare workers), but glad for holistic } \\
\text { treatment approach. } \\
\text { Might lead to greater treatment seeking behaviour and less defaulters. } \\
\text { Less travel costs and time spent accessing different clinics. }\end{array}$ \\
\hline Muddu et $\left.a\right|^{30}$ & Integrated care & $\begin{array}{l}\text { Few responses by patients about integrated HT/HIV care may be an indicator of } \\
\text { limited knowledge about HT in HIV. } \\
\text { Participants reported gaps in clinician documentation (providers record clinical data } \\
\text { in patients' personal books). }\end{array}$ \\
\hline Manavalan et $a l^{31}$ & Fragmented care & $\begin{array}{l}\text { Delayed or non-linkage to care for HT. } \\
\text { Minimal and/or low-quality counselling on HT. } \\
\text { High costs for antihypertensive medication, provider visits, transport to the clinic, } \\
\text { and the expense of a healthy lifestyle. } \\
\text { All respondents conveyed a preference for integrated care due to convenience and } \\
\text { efficiency. }\end{array}$ \\
\hline
\end{tabular}

ART, antiretroviral therapy; HT, hypertension; MACs, Medication Adherence Clubs; NCD, non-communicable disease; PCP, primary care provider; T2D, type 2 diabetes.

\section{HIV-related stigma}

Separate medical records, waiting areas and queues were experienced by some patients in Free State and the healthcare staff in Dr. Kenneth Kaunda and West Rand to increase HIV-related stigma; here illustrated by a patient: Those who [have] HIV, they are isolated to show the people that we are HIV [positive]', ${ }^{14}$ and by a nurse: 'They feel like they are being isolated and they feel stigmatised and that other patients can see. ${ }^{23}$ Despite this, many participants in Free State reported a decrease in HIVrelated stigma due to increased community support and through increased awareness of HIV at the community level. ${ }^{14}$ In Cape Town, South Africa, PLWH experienced reduced stigma when attending integrated healthcare, instead of ART clinics. ${ }^{10}$

In Kenya, the integrated MACs were found to reduce HIV-related stigma as some MAC members experienced HIV being treated like 'any other chronic disease'. While the overall perception was that the MACs reduced the stigma related to HIV, some PLWH that were not using MACs, thought they had to disclose their HIV status to join the clubs, thus fearing of being stigmatised, if someone from their community recognised them. This was, however, not a requirement for joining the clubs. This can be understood in the context of some non-MAC patients explaining the little knowledge they had of the existence of the clubs, while others found the eligibility criteria for the clubs unclear. ${ }^{22} 26$

In Thailand, people living with comorbid HIV and T2D uttered a desire for more privacy regarding their HIV treatment: 'I think if the hospital can separate HIV patients from [others] to make it more private, it'll be good'(patient). ${ }^{27}$ Whether this wish for more privacy was related to HIV-related stigma is not mentioned explicitly in the article.

One study received few responses on patient perspectives which led the authors to hypothesise that patients had little information on HT. ${ }^{30}$ In a study in Northern Tanzania among PLWH and comorbid HT attending nonintegrated (separate) care participants reported delayed or non-linkage to HT care, low quality or minimal counselling on HT and thus expressed a preference for integrated care due to convenience and efficiency. ${ }^{31}$

\section{DISCUSSION}

In this scoping review, we found that patient perspectives and experiences on integrated care for HIV, diabetes and HT were mostly positive, in particular reduced HIVrelated stigma, reduced travel and treatment costs and a more holistic person-centred care.

We identified 13 articles eligible for this scoping review after applying a broad search strategy including publications between 1990 and 2021 with no geographical restrictions. This illustrates the limited number of publications regarding patient perspectives on healthcare integration of HIV, T2D and HT services. Of note, all published material was from within the last 5 years (2016-2021), indicating that this is an emerging research priority. Clearly, most research on patient perspectives has been conducted in SSA with only one article from North America ${ }^{28}$ and one from Asia ${ }^{27}$ while none of the other continents were represented. However, this might not be surprising as a rapid increase in the burden of diabetes, HT and other NCDs is meeting a growing population of PLWH in many countries in SSA. This epidemiological transition 
resulting in a double burden of disease leaves many healthcare systems overburdened. ${ }^{6}$ Interestingly, the only study from a high income setting (Duke University, USA) reported that the PLWH interviewed were highly satisfied with integrated care and preferred receiving primary care from their HIV-physician due to the high degree of continuity of care. This is in contrast to studies from SSA, where participants often experienced a lack of continuity of care in integrated care. This might reflect the high staff turn-over and treatment of PLWH or PLWNCD by healthcare professionals other than physicians.

The study settings could be divided into whether they had integrated care or not. Six studies, all conducted in SSA, tended to have some degree of integrated care, while seven studies reported on fragmented or partially fragmented care. A majority of the studies from SA ( $n=6)$ used the ICDM mode ${ }^{32}$ to conceptualise healthcare integration. However, there was a discrepancy between how healthcare integration was conceptualised by the ICDM model and the actual infrastructures in these study settings, for example, many of the places still having separate care for HIV and T2D. ${ }^{21} 2426$

The diversity of concepts used to assess patient perspectives, underlines the complexity of the topic, and made it difficult to compare these concepts, however, some similarities were identified, indicating that some degree of universality exists when it comes to the needs and wishes of patients. The patient perspectives regarding travel and treatment costs, continuity of care and appointment systems, waiting times at the facilities and HIV-related stigma were identified as the most important themes.

All the studies conducted in fragmented healthcare settings in SSA mentioned travel (and partly treatment) costs as a major burden due to the limited financial resources of patients. ${ }^{21} 2426282931$

There is no doubt that more integrated care could be cost and time-saving for these patients, though cost saving is not mentioned directly in any of the studies conducted in integrated healthcare settings.

Those accessing integrated care were usually satisfied with the holistic and coherent care received and reduced stigma due to attending a general clinic with non-HIV patients. However, more rigid appointment systems, a lack of continuity of care with conflicting messages from changing healthcare providers and long waiting times at facilities were experienced as downsides in some healthcare settings.

Among those using integrated care, some patients expressed areas of improvement. Patients from one study suggested improvements in relation to access to services for sudden-onset illnesses. ${ }^{25}$ One approach for this problem could be to have some emergency appointmenttimes every day at the clinics, which was found to increase patient satisfaction in a publication by Richter et al. ${ }^{33} \mathrm{Staff}$ shortage,$^{1425}$ long waiting times prior to consultations ${ }^{34}$ and patients not knowing the existence of MACs, which provide fast access to medication ${ }^{22}{ }^{26}$ reflect the lack of (efficient) used of resources. In general, better coverage with appropriately qualified healthcare workers is needed to ensure reliable healthcare services. ${ }^{23}$

In general, the findings of this review point towards the overarching challenge of integrative care to synchronise vertical, disease-oriented care with horizontal health systems strengthening programmes. The ideal being to be able to draft health service delivery programmes aimed at specific diseases in a manner that at the same time may drive improvement in the wider health system-a diagonal approach. ${ }^{35}$

\section{Strengths and limitations}

To the best of our knowledge, this is the first systematic scoping review to assess patient perspectives on integration of healthcare for HIV and NCDs. The scoping review methodology and broad search terms, reflected in more than 5500 initial records identified, ensure a high sensitivity of our search strategy.

A limitation of the current scoping review is the singular focus on T2D and HT as indicator conditions. Other important diseases for integration would be mental health, cardiovascular disease or chronic kidney disease. However, T2D and HT represent the common, major chronic conditions in SSA. Another limitation is that grey literature was not included in the search. However, cursory searches in major search engines and reference lists of included articles have not provided additional findings. In addition, the perspectives of healthcare workers would be of interest but were not assessed in the current review.

A further weakness is that there were no studies of integrated care and management for HIV, DM and HTNin other words a clinic that can manage patients with either HIV, DM, HTN or combinations of these. Most of the studies involved only a small component of care to be integrated (eg, screening) or they involved adding diabetes and HT services to HIV programmes, which excludes people without HIV from integrated care. Of note, no studies from Europe were identified, however, some hospitals in Europe are working on integrating services (eg, the multidisciplinary setup in Modena, Italy (unpublished, authors correspondence). There is a clear need for more research, including longitudinal and interventional studies from different healthcare settings.

\section{CONCLUSION}

Only few articles in the peer-reviewed literature, with a limited geographical scope, were identified. However, all the publications were from 2016 to 2021, and the majority of the articles were from SSA $(n=11)$, indicating that the topic is an emerging research priority in this region.

Patient's experiences with integrated care were reduced HIV-related stigma, reduced travel and treatment costs and more holistic person-centred care. Prominent concerns were long waiting times at clinics and a lack of continuity of care with the same provider. Non-integrated care was perceived as time-consuming and more expensive. Integration can save resources for health services, 
which if reinvested can yield benefits for PLWNCDs and PLWH alike. If additional services are simply added to existing ones (eg, diabetes screening within HIV programmes) it will lead to increased waiting times for participants. The articles included in this review are an important source of evidence for patient-centred integration of HIV and NCD healthcare services, potentially also as important evidence and lessons for high-income settings (eg, Europe). There is a paucity of evidence and further longitudinal and interventional evidence from a more diverse range of healthcare systems is desirable.

\section{Author affiliations}

${ }^{1}$ Department of Public Health, Aarhus University, Aarhus, Denmark

${ }^{2}$ Danish Non-communicable Diseases Alliance, Copenhagen, Denmark

${ }^{3}$ Department of Infectious Disease, Rigshospitalet, University of Copenhagen, Copenhagen, Denmark

${ }^{4}$ Department of International Public Health, Liverpool School of Tropical Medicine, Liverpool, UK

${ }^{5}$ Kenya Diabetes Management and Information Centre, Nairobi, Kenya

${ }^{6}$ Shree Hindu Mandal Hospital, Dar es Salaam, Tanzania, United Republic of

${ }^{7}$ Centre for Global Health, Department of Public Health, Aarhus University, Aarhus, Denmark

${ }^{8}$ Centre of Excellence for Health, Immunity and Infections (CHIP), Rigshospitalet, University of Copenhagen, Copenhagen, Denmark

Acknowledgements We thank the medical librarian of Aarhus University for advising on the search strategy, which databases to search and to adapt the search strategy to different databases.

Contributors CK, SS and PK conceived of the study. SS, CK and PK contributed to data collection and analysis. SS, OK, SJ, CK, KR, PK and CK were involved in drafting and approving the final manuscript. CK was the guarantor.

Funding The authors have not declared a specific grant for this research from any funding agency in the public, commercial or not-for-profit sectors.

Competing interests None declared.

Patient consent for publication Not applicable.

Ethics approval No ethical approval was required as only secondary data were investigated and used.

Provenance and peer review Not commissioned; externally peer reviewed. Data availability statement Data extraction sheets are available on request. Supplemental material This content has been supplied by the author(s). It has not been vetted by BMJ Publishing Group Limited (BMJ) and may not have been peer-reviewed. Any opinions or recommendations discussed are solely those of the author(s) and are not endorsed by BMJ. BMJ disclaims all liability and responsibility arising from any reliance placed on the content. Where the content includes any translated material, BMJ does not warrant the accuracy and reliability of the translations (including but not limited to local regulations, clinical guidelines, terminology, drug names and drug dosages), and is not responsible for any error and/or omissions arising from translation and adaptation or otherwise.

Open access This is an open access article distributed in accordance with the Creative Commons Attribution Non Commercial (CC BY-NC 4.0) license, which permits others to distribute, remix, adapt, build upon this work non-commercially, and license their derivative works on different terms, provided the original work is properly cited, appropriate credit is given, any changes made indicated, and the use is non-commercial. See: http://creativecommons.org/licenses/by-nc/4.0/.

\section{ORCID iDs}

Shabbar Jaffar http://orcid.org/0000-0002-9615-1588

Christian Kraef http://orcid.org/0000-0002-5224-0335

\section{REFERENCES}

1.2020 global AIDS update - seizing the moment - tackling entrenched inequalities to end epidemics. Geneva, Switzerland
UNAIDS; 2021. https://www.unaids.org/en/resources/documents/ 2020/global-aids-report [Accessed 2th November 2021].

2 Kraef C, Kallestrup P. After the Astana declaration: is comprehensive primary health care set for success this time? BMJ Glob Health 2019;4:e001871.

3 Mercer T, Chang AC, Fischer L, et al. Mitigating the burden of diabetes in sub-Saharan Africa through an integrated diagonal health systems approach. Diabetes Metab Syndr Obes 2019;12:2261-72.

4 Bosire EN, Mendenhall E, Norris SA, et al. Patient-Centred care for patients with diabetes and HIV at a public tertiary hospital in South Africa: an ethnographic study. Int J Health Policy Manag 2020. doi:10.34172/ijhpm.2020.65. [Epub ahead of print: 06 May 2020].

5 Vorkoper S, Kupfer LE, Anand N, et al. Building on the HIV chronic care platform to address noncommunicable diseases in sub-Saharan Africa: a research agenda. AIDS 2018;32 Suppl 1:S107-13.

6 Atun R, Davies JI, Gale EAM, et al. Diabetes in sub-Saharan Africa: from clinical care to health policy. Lancet Diabetes Endocrinol 2017;5:622-67.

7 NCD Countdown 2030 collaborators. Ncd countdown 2030: worldwide trends in non-communicable disease mortality and progress towards sustainable development goal target 3.4. Lancet 2018;392:1072-88.

8 Kraef C, Juma PA, Mucumbitsi J, et al. Fighting non-communicable diseases in East Africa: assessing progress and identifying the next steps. BMJ Glob Health 2020;5:e003325.

9 Adeyemi O, Lyons M, Njim T, et al. Integration of non-communicable disease and HIV/AIDS management: a review of healthcare policies and plans in East Africa. BMJ Glob Health 2021;6:e004669.

10 Peer N, de Villiers A, Jonathan D, et al. Care and management of a double burden of chronic diseases: experiences of patients and perceptions of their healthcare providers. PLOS One 2020;15:e0235710.

11 Duffy M, Ojikutu B, Andrian S, et al. Non-Communicable diseases and HIV care and treatment: models of integrated service delivery. Trop Med Int Health 2017;22:926-37.

12 Njuguna B, Vorkoper S, Patel P, et al. Models of integration of HIV and noncommunicable disease care in sub-Saharan Africa: lessons learned and evidence gaps. AIDS 2018;32 Suppl 1:S33-42.

13 Van Hout M-C, Bachmann M, Lazarus JV, et al. Strengthening integration of chronic care in Africa: protocol for the qualitative process evaluation of integrated HIV, diabetes and hypertension care in a cluster randomised controlled trial in Tanzania and Uganda. BMJ Open 2020;10:e039237.

14 Rawat A, Uebel K, Moore D, et al. Patient Responses on Quality of Care and Satisfaction with Staff After Integrated HIV Care in South African Primary Health Care Clinics. J Assoc Nurses AIDS Care 2018;29:698-711.

15 Asghari S, Maybank A, Hurley O, et al. Perspectives of people living with HIV on access to health care: protocol for a scoping review. JMIR Res Protoc 2016;5:e71.

16 Kall M, Marcellin F, Harding R, et al. Patient-Reported outcomes to enhance person-centred HIV care. Lancet HIV 2020;7:e59-68.

17 Pham MT, Rajić A, Greig JD, et al. A scoping review of scoping reviews: advancing the approach and enhancing the consistency. Res Synth Methods 2014;5:371-85.

18 Arksey H, O'Malley L. Scoping studies: towards a methodological framework. Null 2005;8:19-32.

19 Peters MDJ, Godfrey CM, Khalil H, et al. Guidance for conducting systematic scoping reviews. Int J Evid Based Healthc 2015;13:141-6.

20 Tricco AC, Lillie E, Zarin W, et al. PRISMA extension for scoping reviews (PRISMA-ScR): checklist and explanation. Ann Intern Med 2018;169:467-73.

21 Matima R, Murphy K, Levitt NS, et al. A qualitative study on the experiences and perspectives of public sector patients in Cape town in managing the workload of demands of HIV and type 2 diabetes multimorbidity. PLoS One 2018;13:e0194191.

22 Venables E, Edwards JK, Baert S, et al. "They just come, pick and go." The Acceptability of Integrated Medication Adherence Clubs for HIV and Non Communicable Disease (NCD) Patients in Kibera, Kenya. PLoS One 2016;11:e0164634.

23 Lebina L, Oni T, Alaba OA, et al. A mixed methods approach to exploring the moderating factors of implementation fidelity of the integrated chronic disease management model in South Africa. BMC Health Serv Res 2020;20:617.

24 Bosire EN. Patients' experiences of comorbid HIV/AIDS and diabetes care and management in Soweto, South Africa. Qual Health Res 2021;31:373-84.

25 Ameh S, Klipstein-Grobusch K, D'ambruoso L, et al. Quality of integrated chronic disease care in rural South Africa: user and provider perspectives. Health Policy Plan 2017;32:257-66. 
26 Knight L, Schatz E, Mukumbang FC. "I attend at Vanguard and I attend here as well": barriers to accessing healthcare services among older South Africans with HIV and non-communicable diseases. Int $J$ Equity Health 2018;17:147.

27 Moise RK, Srithanaviboonchai K, Alsolami A, et al. The patientprovider continuum of care: narratives of people living with comorbid HIV and diabetes in northern Thailand. J Patient Exp 2020;7:749-57.

28 Mkumba L, Muiruri C, Garg K, et al. Perspectives of chronic disease management among persons with HIV: a qualitative study. Patient Prefer Adherence 2021;15:49-55.

29 Moucheraud C, Hing M, Seleman J, et al. Integrated care experiences and out-of-pocket expenditures: a cross-sectional survey of adults receiving treatment for HIV and hypertension in Malawi. BMJ Open 2020;10:e032652.

30 Muddu M, Tusubira AK, Nakirya B, et al. Exploring barriers and facilitators to integrated hypertension-HIV management in Ugandan HIV clinics using the consolidated framework for implementation research (CFIR). Implement Sci Commun 2020;1:45

31 Manavalan P, Minja L, Wanda L, et al. "It's because I think too much": Perspectives and experiences of adults with hypertension engaged in HIV care in northern Tanzania. PLoS One 2020;15:e0243059.

32 Mahomed O, Freeman M, Asmall S. An integrated chronic disease management Model- a diagonal approach to health system strengthening. Int J Integr Care 2014;14.

33 Richter JP, Downs L, Beauvais B, et al. Does the proportion of sameday and 24-hour appointments impact patient satisfaction? Qual Manag Health Care 2017;26:22-28.

34 World Health Organization. Integrated care models: an overview, 2016. Available: https://www.euro.who.int/en/health-topics/Healthsystems/health-services-delivery/publications/2016/integrated-caremodels-an-overview-2016 [Accessed 23 Mar 2021]
35 Frenk J, Gómez-Dantés O, Knaul FM. The Health Systems Agenda: Prospects for the Diagonal Approach. In: The Handbook of Global Health Policy; John Wiley \& Sons, Ltd, 2014: 425-39.

36 UNAIDS Terminology Guidelines [Internet] 2015.

37 World Health Organization. Noncommunicable diseases. Available: https://www.who.int/news-room/fact-sheets/detail/ noncommunicable-diseases [Accessed 12 Jan 2021].

38 World Health Organization. Innovative care for chronic conditions: building blocks for action, 2002

39 Shippee ND, Shah ND, May CR, et al. Cumulative complexity: a functional, patient-centered model of patient complexity can improve research and practice. J Clin Epidemiol 2012;65:1041-51.

40 Mahomed $\mathrm{OH}$, Asmall S. Development and implementation of an integrated chronic disease model in South Africa: lessons in the management of change through improving the quality of clinical practice. Int J Integr Care 2015;15:e038.

41 World Health Organization. Integrated health services - what and why? WHO, 2008.

42 Donabedian A. The quality of care. JAMA 1988;260:1743-8.

43 MacGregor H, McKenzie A, Jacobs T, et al. Scaling up art adherence clubs in the public sector health system in the Western Cape, South Africa: a study of the institutionalisation of a pilot innovation. Global Health 2018:14:40.

44 Singer M, Bulled N, Ostrach B, et al. Syndemics and the biosocial conception of health. Lancet 2017;389:941-50

45 Sogarwal R, Mehra S. Approaches to address Ncd among PLHIV in low and middle income counties. Journal of AIDS \& Clinical Research 2015;06.

46 Cheng QJ, Engelage EM, Grogan TR, et al. Who provides primary care? an assessment of HIV patient and provider practices and preferences. J AIDS Clin Res 2014;5. 